\title{
The effect of social determinants on oral health knowledge and patient's bill of rights
}

\section{Wpływ determinant socjalnych na wiedzę dotyczącą zdrowia jamy ustnej oraz uprawnienia pacjenta}

\author{
Masoud Eisa Khajelou ${ }^{1, B, D}$, Vahideh Zarea Gavgani ${ }^{1, A, E, F}$, Mohammad Asghari Jafarabadi², ${ }^{2, C}$ \\ 1 Department of Medical Library and Information Science, Faculty of Management and Medical Informatics, Tabriz University of Medical Sciences, Iran \\ ${ }^{2}$ Department of Statistics and Epidemiology, Faculty of Health, Tabriz University of Medical Sciences, Iran \\ A - research concept and design; $\mathrm{B}$ - collection and/or assembly of data; $\mathrm{C}$ - data analysis and interpretation; \\ $D$ - writing the article; $E$ - critical revision of the article; $F$ - final approval of the article
}

Address for correspondence

Vahideh Zarea Gavgani

E-mail: zarehv@tbzmed.ac.ir

Funding sources

None declared

Conflict of interest

None declared

Acknowledgements

We would like to thank the Office of the Vice Chancellor for Research (VCR) of Tabriz University of Medical Sciences, Iran, for funding this study.

Received on December 10, 2017

Reviewed on January 14, 2018

Accepted on March 7, 2018

DOI

$10.17219 / \mathrm{dmp} / 86358$

Copyright

() 2018 by Wroclaw Medical University

and Polish Dental Society

This is an article distributed under the terms of the

Creative Commons Attribution Non-Commercial License

(http://creativecommons.org/licenses/by-nc-nd/4.0/)

\section{Abstract}

Background. Health knowledge is a requirement in healthcare and having a higher level of health knowledge helps to promote a satisfactory health status. Also, patients have specific rights within the healthcare system, but sometimes they are not aware of their rights. These issues are highly affected by social determinants.

Objectives. The goal of this study was to assess the social determinants of oral health knowledge and the awareness of patient's rights.

Material and methods. This was a cross-sectional study conducted on patients referred to private offices and dental clinics in Tabriz, Iran. The study sample consisted of 500 patients and was selected by random sampling. A researcher-made questionnaire was used to collect data.

Results. The highest number of the patients (31.9\%) were $25-34$ years old; $62.2 \%$ of the participants were female and $37.8 \%$ were male. Regarding religion, on a 1-10 scale, the majority of the respondents (26.6\%) had scored themselves 8 . As for oral health knowledge, $84.8 \%$ believed that reducing sugar consumption prevents tooth decay and $96.9 \%$ declared that stopping smoking is effective in reducing oral diseases. Regarding patients' awareness of the right to access their medical records, only $40 \%$ stated that they have such right and 34.2\% declared "I don't know", while $25.8 \%$ believed they have no right to access their medical records.

Conclusions. Education level plays a critical role in improving the oral health knowledge level and awareness of patient's rights. Educational programs by the mass media and healthcare centers can help patients achieve a higher level of oral health knowledge and awareness of their rights.

Key words: oral health, patient's rights, health knowledge, attitudes, practice

Słowa kluczowe: zdrowie jamy ustnej, prawa pacjenta, wiedza o zdrowiu, nastawienie, praktyka 
Health knowledge is a fundamental prerequisite in healthcare. ${ }^{1}$ People's health as individuals and as a community has a great impact on the development of society. Tooth decay and oral diseases are common even in developed countries and have a profound impact on the individual's health and, consequently, on the health of the society. $^{2}$ Within this context, studies have shown that there is a correlation between having broader knowledge and improved health. ${ }^{3}$ Also, everyone has specific rights within the healthcare system, which have to be respected by the health staff and patients should be aware of these rights if high quality healthcare services are to be delivered. ${ }^{4}$ During the last few decades, major reforms have been conducted in providing healthcare services. For years, healthcare staff believed that they can make the best decisions regarding patients without paying attention to their rights. ${ }^{5}$

As for health-related behaviors, different factors such as economic and social are considered. As an example, the education level has an influence on health-related behaviors. Those behaviors, e.g., brushing twice a day and applying fluoride-containing tooth paste and reducing sugar intake, were more common among senior students compared to junior. ${ }^{6}$ Having basic information about oral health, followed by preventive actions, is essential in improving self-care behaviors. Although there is an emphasis on proper knowledge and information in the mentioned fields, in Italy, for example, there is not enough information about health behavior pertaining to oral health among people. ${ }^{7}$ Studies have shown that there is a strong correlation between individuals' quality of life and health status. A study conducted by Watt demonstrated that individuals who have a lower income and education level, have a lower health status as well. ${ }^{8}$ Another study, performed by Petersen, showed that demographic factors have an influence on behavioral factors and, consequently, affect the health status. ${ }^{9}$ Few studies were carried out on the effect of social factors on oral health.

The aim of this study was to assess the effect of social determinants on the oral health knowledge and on awareness of the patient's rights.

\section{Material and methods}

This is a descriptive, cross-sectional study conducted on patients referred to dentistry clinics and dental office in Tabriz, Iran. The study sample consisted of 500 patients selected by simple random sampling. A researcher-made questionnaire was used to collect data. The reliability of the questionnaire was verified by 10 members of a panel of dentists and its validity was confirmed by Cronbach's alpha 0.88 and 0.812 , respectively. Tabriz city is divided into 10 districts. A total number of 600 clinics and dental offices were identified. In each district, according to the number of clinics and offices, $20 \%$ of them were chosen randomly. Within each clinic and office, 5 samples were selected randomly. ${ }^{10}$

To collect data, the aim of the study was explained to the participants clearly and if they intended to participate, the questionnaire was given to them and was collected after it had been completed.

The questionnaire consisted of 4 parts:

1) demographic information;

2) knowledge about oral health;

3) social determinants; and

4) patient's rights.

Religion factor was measured as a self-report on a $1-10$ scale.

The correlation between variables was analyzed using SPSS software package v. 23.0 for Windows (IBM Corp., Armonk, USA) and the Pearson's $\chi^{2}$ test was applied. A p-value $<0.05$ was considered significant.

Inclusion criteria consisted of min 18 years of age, literacy and consent to participate in the study. This study was approved by the ethical committee of Tabriz University of Medical Sciences, Iran, with the following ethical code: IR.TBZMED.REC.1395.50.

\section{Results}

The statistical analyses were conducted on the collected data. The highest number of participants (31.9\%) were 25-34 years old, $23.8 \%$ of them were $35-44$ years old, $22.5 \%$ were $45-59$ years old, $12.5 \%$ were $18-24$ years old, and $9.4 \%$ were above 60 years of age. Regarding gender, $62 \%$ of the participants were female and the rest (38\%) were male. As for marital status, $73 \%$ were married and only $27 \%$ were single. The majority of the participants (38.2\%) had bachelor's degree; the holders of a high school and "some school" diploma consisted of $29.4 \%$ and $13.7 \%$ of the study group, respectively (Table 1 ).

Regarding religion, on a 1-10 scale, the highest number of the respondents (26.6\%) scored themselves 8 , while $24.3 \%$ chose a score of 6 . The lowest score was 5 and was chosen by $7.9 \%$ of the participants.

One of the signs of a health-centered culture in a family can be encouraging children to take care of oral health, especially by brushing the teeth. Therefore, the participants were asked if their parents encouraged them to brush their teeth since their childhood. A little more than half of the respondents (54.4\%) declared that their parents were encouraging them to brush their teeth since childhood; but, on the other hand, 1/3 of the participants (33.5\%) stated that their parents had no role in encouraging them to brush their teeth. Pertaining to financial issues in regard to seeking treatment, $22.4 \%$ stated that financial difficulties prevented them to treat oral diseases, while $22 \%$ responded they had no such problems and $55.6 \%$ chose "no comment". 
Table 1. Demographic characteristics of the study participants

\begin{tabular}{|c|c|c|c|}
\hline \multicolumn{2}{|c|}{ Characteristics } & Frequency & Percentage \\
\hline \multirow{5}{*}{ Age } & $18-24$ & 60 & 12.5 \\
\hline & $25-34$ & 153 & 31.9 \\
\hline & $35-44$ & 114 & 23.8 \\
\hline & $45-59$ & 108 & 22.5 \\
\hline & $>60$ & 45 & 9.4 \\
\hline \multirow{2}{*}{ Gender } & male & 182 & 37.8 \\
\hline & female & 299 & 62.2 \\
\hline \multirow{2}{*}{ Marital status } & single & 130 & 27.0 \\
\hline & married & 352 & 73.0 \\
\hline \multirow{6}{*}{ Education } & some school & 65 & 13.7 \\
\hline & high school & 140 & 29.4 \\
\hline & some college & 39 & 8.2 \\
\hline & bachelor's degree & 182 & 38.2 \\
\hline & master's degree & 35 & 7.4 \\
\hline & $\mathrm{PhD}$ & 15 & 3.2 \\
\hline
\end{tabular}

\section{Knowledge and awareness}

In the knowledge and awareness section, $84.8 \%$ of the participants believed that reducing sugar consumption prevents tooth decay. Also, 80.5\% thought that consuming fruit and vegetables is effective in preventing oral diseases and 13.3\% declared that they "don't know". Regarding the effect of smoking, 96.9\% declared that stopping smoking is beneficial in the reduction of oral diseases. Furthermore, $62.2 \%$ believed that gum diseases trigger losing teeth, but $31.6 \%$ held no such an opinion. In addition, $97.1 \%$ mentioned that having pretty teeth improves their self-confidence and $95.1 \%$ thought that it is an indicator of social prestige (Table 2).

\section{Patient's rights}

As for the awareness of patient's rights, $94.8 \%$ of the participants believed that dentists must explain to the patients the quality of the treatment and treatment methods before and after treatment. Regarding the right to access their medical records, only $40 \%$ stated that they have such right, 34.2\% declared "I don't know" and 25.8\% believed they have no right to access their medical records. Participants were asked if they have the right to consult other dentists and withdraw from treatment; $66 \%$ of them answered "yes", 18.4\% answered "I don't know" and 15.7\% chose "no". Regarding harm or injuries to teeth by dentist during treatment, participants were asked if they have the right to file a complaint against a dentist and the majority (93.9\%) believed they have such right (Table 3).

To assess the correlations between the education level/ marital status, reducing of sugar consumption and tooth decay, the Pearson's $\chi^{2}$ test was applied. All (100\%) of the
Table 2. Knowledge and awareness of the study participants regarding the factors affecting oral health and the social impact of having attractive teeth

\begin{tabular}{|c|c|c|c|}
\hline Question & Answer & Frequency & Percentage \\
\hline \multirow{3}{*}{$\begin{array}{l}\text { Does reducing } \\
\text { sugar consumption } \\
\text { prevent tooth decay? }\end{array}$} & no & 48 & 10.0 \\
\hline & yes & 408 & 84.8 \\
\hline & I don't know & 25 & 5.2 \\
\hline \multirow{3}{*}{$\begin{array}{l}\text { Is consuming fruit } \\
\text { and vegetables effective } \\
\text { in preventing oral diseases? }\end{array}$} & no & 30 & 6.2 \\
\hline & yes & 387 & 80.5 \\
\hline & I don't know & 64 & 13.3 \\
\hline \multirow{3}{*}{$\begin{array}{l}\text { Is stopping smoking effective } \\
\text { in the reduction } \\
\text { of oral diseases? }\end{array}$} & no & 2 & 0.4 \\
\hline & yes & 463 & 96.9 \\
\hline & I don't know & 13 & 2.7 \\
\hline \multirow{3}{*}{$\begin{array}{l}\text { Does gum diseases } \\
\text { cause tooth loss? }\end{array}$} & no & 30 & 6.2 \\
\hline & yes & 299 & 62.2 \\
\hline & I don't know & 152 & 31.6 \\
\hline \multirow{3}{*}{$\begin{array}{l}\text { Does having attractive } \\
\text { teeth improve } \\
\text { your self-confidence? }\end{array}$} & no & 4 & 0.8 \\
\hline & yes & 461 & 97.1 \\
\hline & I don't know & 10 & 2.1 \\
\hline \multirow{3}{*}{$\begin{array}{l}\text { Are attractive teeth } \\
\text { an indicator } \\
\text { of social prestige? }\end{array}$} & no & 13 & 2.8 \\
\hline & yes & 447 & 95.1 \\
\hline & I don't know & 10 & 2.1 \\
\hline
\end{tabular}

holders of "some college" diploma and a PhD degree believed in the effect of reducing sugar consuming on tooth decay, while $97.2 \%$ of the holders of a bachelor's degree, $85.3 \%$ of the holders of master's degree, $72.7 \%$ of the holders of high school diploma, and $67.2 \%$ of the holders of "some school" diploma answered "yes" to that question ( $\mathrm{p}=0.016$ ). As for the marital status, the majority of single participants $(96.1 \%)$ believed that reducing sugar consumption is effective in preventing tooth decay; the result was $80.4 \%$ among married participants $(\mathrm{p}=0.031)$.

Table 3. Knowledge and awareness of the study participants regarding patient's rights

\begin{tabular}{|c|c|c|c|}
\hline Question & Answer & Frequency & Percentage \\
\hline \multirow{3}{*}{$\begin{array}{l}\text { Should dentist explain the } \\
\text { quality and the treatment } \\
\text { method to the patients } \\
\text { before and after treating? }\end{array}$} & no & 3 & 0.6 \\
\hline & yes & 455 & 94.8 \\
\hline & I don't know & 22 & 4.6 \\
\hline \multirow{3}{*}{$\begin{array}{l}\text { Do you have the right } \\
\text { to access your } \\
\text { medical records? }\end{array}$} & no & 124 & 25.8 \\
\hline & yes & 192 & 40.0 \\
\hline & I don't know & 164 & 34.2 \\
\hline \multirow{3}{*}{$\begin{array}{l}\text { Do have the right to consult } \\
\text { other dentists and withdraw } \\
\text { from the treatment? }\end{array}$} & no & 75 & 15.7 \\
\hline & yes & 316 & 66.0 \\
\hline & I don't know & 88 & 18.4 \\
\hline \multirow{3}{*}{$\begin{array}{l}\text { Do you have the right to } \\
\text { complain if the dentist } \\
\text { causes harm or injuries to } \\
\text { your teeth during treatment? }\end{array}$} & no & 30 & 6.2 \\
\hline & yes & 299 & 62.2 \\
\hline & I don't know & 152 & 31.6 \\
\hline \multirow{3}{*}{$\begin{array}{l}\text { Does having attractive } \\
\text { teeth improve } \\
\text { your self-confidence? }\end{array}$} & no & 3 & 0.6 \\
\hline & yes & 447 & 93.9 \\
\hline & I don't know & 26 & 5.5 \\
\hline
\end{tabular}


Regarding the correlation of religion scale score and the effect of reducing sugar consumption in preventing tooth decay, the majority of the participants $(74.3 \%$ of the patients who scored themselves 8 and above, $81.1 \%$ of those who chose 6 or 7 and $77.6 \%$ of those who chose 5 ) believed that reducing sugar consumption is effective in preventing tooth decay $(\mathrm{p}=0.081)$.

As for the correlation between education and access to medical records, $85.7 \%$ of the holders of a master's degree, $71.4 \%$ of $\mathrm{PhD}$ holders, $46.7 \%$ of the holders of bachelor's degree, $39.9 \%$ of high school diploma holders, and $26.3 \%$ of the holders of "some college" diploma answered "yes". The highest number of participants who answered "no" were the holders of "some school" diploma with a 92.92\% score.

As for the correlation between gender and awareness of the right to access the medical records, $41.4 \%$ of the females believed that they have the right to access their medical records, while the result was $38 \%$ among males $(\mathrm{p}=0.62)$.

\section{Discussion}

This study was conducted to assess the effect of social determinants on the oral health of dental patients. The results of this study showed that the majority of the patients were familiar with patient's rights. No previous study in Iran was performed on the dental patients' awareness of their rights. However, research performed by Bazmi et al. in 2015 on the patients' awareness of their rights reported that the level of awareness was $80 \%{ }^{11}$ The results of the current study demonstrated that education level has a significant impact on the level of awareness of patient's rights. Most of the contributors who held university degrees believed that they have the right to access their medical records; meanwhile, most of the patients with low education levels believed they had no such right. These results revealed the profound effect of education level on the patients' awareness of their rights. This shows that if people are encouraged to continue education on higher levels, as patients they will be more aware of their rights. A higher level of education enables and empowers people to receive more information regarding health-related issues, such as patient's rights. They also get training to use different sources of information such as digital sources, which can help them obtain widespread types of information, as well as communicate and consult with others easily. The results of this study proved that there is a significant correlation between education level and awareness of the right to have access to medical records; they are in line with a study conducted by Zülfikar and Ulusoy in Turkey. ${ }^{12}$ Furthermore, research conducted by Mastaneh and Mouseli concluded that there is a strong correlation between education level and the patients awareness of their right to access their medical records. One possible explanation of this conclusion is that education helps people make informed decisions pertaining to health issues. ${ }^{13}$ In addition, the correlation between education and health-improving behaviors was observed in studies such as the one conducted by Abuladze et al. ${ }^{14}$ The reason might be the ability to use new types of sources of information about health improvement. Better-educated people might also have more interest in staying up-to-date with health-related issues. Although other studies, such as the one conducted by Rajesh et al., showed that there is a correlation between being religious and oral healthrelated behaviors, the current study showed no significant correlation. ${ }^{15}$ A possible explanation of this is that most Iranians are religious.

In the current study, there was no significant correlation between gender and awareness of patient's rights. Today, because of equality in achieving education, with both men and women benefiting, gender does not constitute an effective factor in the awareness of patient's rights. Both men and women in most of the countries have access to the same level of education and the highest levels of education are available for both men and women. These results are in line with the results of the study carried out by Mastaneh and Mouseli. ${ }^{13}$ The results of the study performed by Ansari et al. confirm the results of the present study. ${ }^{16}$

In the health knowledge field, those who have a higher level of education have a higher level of health knowledge as well. The results of the study carried out by Macek et al. showed the significant correlation between education level and health knowledge. ${ }^{17}$ This significant correlation can be understood in the following way: those who have a higher level of education are able to use different sources and also want to obtain information about health. People who have a higher level of education know more about the importance of health promotion and the effect of health knowledge on health quality. In the current study, a significant correlation was observed between the education level and health knowledge, which is in line with the studies conducted by Yaghobian et al. and Wirth et al., which revealed that those who have a higher level of education, had broader knowledge about health as well. ${ }^{18,19}$

Regarding the correlation between marital status, health knowledge and awareness of patient's rights, married people had higher levels of such knowledge compared to single people, which is in line with research conducted by Yuan et al. ${ }^{20}$ One possible explanation of this is that couples share their knowledge and spend time together discussing health-related issues.

\section{Conclusions}

This study showed that the education level is significantly correlated with the level of knowledge about oral health and with awareness of patient's rights. Financial issues are a barrier in seeking treatment and insurance poli- 
cies should cover oral and dental diseases. Policy makers need to encourage the public to obtain higher education. It is also recommended to inform the public on their rights and proper nutrition and to help them in quitting smoking, using mass media and healthcare centers.

\section{References}

1. Kumar H, Behura SS, Ramachandra S, Nishat R, Dash KC, Mohiddin G. Oral health knowledge, attitude, and practices among dental and medical students in Eastern India: A comparative study. J Int Soc Prev Community Dent. 2017;7:58-63.

2. Rao BV, Babu AS, Kamalsha S, Rao MS, Karthik K. Oral health status and treatment needs of Gunj marketing yard laborers of Raichur City, Karnataka. J Pharm Bioallied Sci. 2017;9:195-200.

3. Al-Ansari J, Honkala E, Honkala S. Oral health knowledge and behavior among male health sciences college students in Kuwait. BMC Oral Health. 2003;3:2.

4. Özdemir MH, Can IÖ, Ergönen AT, Hilal A, Önder M, Meral D. Midwives and nurses awareness of patients' rights. Midwifery. 2009;25:756-765.

5. Zere E, Mandlhate C, Mbeeli T, Shangula K, Mutirua K, Kapenambili W. Equity in health care in Namibia: Developing a needs-based resource allocation formula using principal components analysis. Int J Equity Health. 2007;6:3. doi: 10.1186/1475-9276-6-3

6. Sharda AJ, Shetty S. A comparative study of oral health knowledge, attitude and behavior of first and final year dental students of Udaipur city, Rajasthan, India. Int J Dent Hyg. 2008;6:347-353.

7. Rimondini L, Zolfanelli B, Bernardi F, Bez C. Self-preventive oral behavior in an Italian university student population. J Clin Periodontol. 2001;28:207-211.

8. Watt RG. From victim blaming to upstream action: Tackling the social determinants of oral health inequalities. Community Dent Oral Epidemiol. 2007;35:1-11.

9. Petersen PE. Sociobehavioural risk factors in dental caries: International perspectives. Community Dent Oral Epidemiol. 2005;33:274-279.

10. Schumacker RE, Lomax RG. A Beginner's Guide to Structural Equa tion Modeling. Mahwah, NJ: Lawrence Erlbaum Associates Publishers; 2004.

11. Bazmi S, Kiani M, Hashemi Nazari SS, Kakavand M, Mahmoodzade R. Assessment of patients' awareness of their rights in teaching hospitals in Iran. Med Sci Law. 2016;56:178-183.

12. Zülfikar F, Ulusoy MF. Are patients aware of their rights? A Turkish study. Nurs Ethics. 2001;8:487-498.

13. Mastaneh Z, Mouseli L. Patients' awareness of their rights: Insight from a developing country. Int J Health Policy Manag. 2013;1:143-146.

14. Abuladze L, Kunder N, Lang K, Vaask S. Associations between selfrated health and health behaviour among older adults in Estonia: A cross-sectional analysis. BMJ Open. 2017;7:e013257.

15. Rajesh G, Seemanthini S, Naik D, Pai K, Rao A. Disparities in ora health behavior among young adults in Mangalore, India: A psychosocial perspective. J Clin Diag Res. 2017;11:Lc17-Lc21.

16. Ansari S, Abeid P, Namvar F, Dorakvand M, Rokhafrooz D. Respect to the bill of patients' rights in the educational hospitals in Ahvaz, Iran. Middle East J Sci Res. 2013;13:440-444.

17. Macek MD, Haynes D, Wells W, Bauer-Leffler S, Cotten PA, Parker RM. Measuring conceptual health knowledge in the context of oral health literacy: Preliminary results. J Public Health Dent. 2010;70:197-204.

18. Yaghobian M, Kaheni S, Danesh M, Abhari FR. Association between awareness of patient rights and patient's education, seeing bill, and age: A cross-sectional study. Glob J Health Sci. 2014;6:55-64.

19. Wirth T, Kozak A, Schedlbauer G, Nienhaus A. Health behaviour, health status and occupational prospects of apprentice nurses and kindergarten teachers in Germany: A cross-sectional study. J Occup Med Toxicol. 2016;11:26. doi: 10.1186/s12995-016-0116-7

20. Yuan F, Qian D, Huang C, et al. Analysis of awareness of health knowledge among rural residents in western China. BMC Public Health. 2015;15:55. doi: 10.1186/s12889-015-1393-2 
